\title{
INDÚSTRIA CULTURAL E FORMAÇÃO DOCENTE: ANÁLISE DE TESES E DISSERTAÇÕES PRESENTES NA CAPES (2014-2018)
}

\author{
INDUSTRIA CULTURAL Y FORMACIÓN DOCENTE: ANÁLISIS DE TESIS Y \\ DISERTACIONES PRESENTES EN LA CAPES (2014-2018)
}

\section{CULTURAL INDUSTRY AND TEACHER TRAINING: ANALYSIS OF THESES AND DISSERTATIONS IN CAPES (2014-2018)}

\author{
Solange Franci Raimundo YAEGASHI ${ }^{1}$ \\ Lucilia Vernaschi de OLIVEIRA ${ }^{2}$ \\ Isaias Batista de OLIVEIRA JÚNIOR ${ }^{3}$
}

RESUMO: Esse estudo insere-se na discussão acerca do atual contexto de formação docente influenciado pelos ditames da indústria cultural. O recorte proposto para o trabalho busca problematizar a referida temática apoiada nos referenciais teóricos da Escola de Frankfurt representada por Theodor W. Adorno, dentre outros pensadores. Com isso, objetivamos analisar o uso da Teoria Crítica da Sociedade utilizada na fundamentação de pesquisas stricto sensu sobre formação docente no Brasil, entre os anos de 2014 a 2018. Os resultados apontam para a importância da teoria adorniana na fundamentação crítica de estudos sobre a formação de professores em nosso país, entendida no processo de produção e consumo capitalista que se vale da arte como manobra de alienação e massificação da grande massa.

PALAVRAS-CHAVE: Adorno. Formação docente. Indústria cultural.

RESUMEN: El estudio se insiere en la discusión acerca del actual contexto de formación docente influenciado por los dictámenes de la industria cultural. El recorte propuesto para el trabajo busca problematizar el dicho tema apoyado en los referenciales teóricos de la Escuela de Frankfurt representada por Theodor W. Adorno, entre otros pensadores. Con ello, tenemos por objeto analizar el uso de la Teoría Crítica de la Sociedad utilizada en la fundamentación de investigaciones stricto sensu sobre formación docente en Brasil, entre los años 2014 y 2018. Los resultados señalan la importancia de la teoría adorniana en la fundamentación crítica de estudios sobre la formación del profesorado en nuestro país, comprendida en el proceso de producción y consumo capitalista que se vale del arte como manobra de alienación y masificación de la gran masa.

PALABRAS CLAVE: Adorno. Formación docente. Industria cultural.

\footnotetext{
${ }^{1}$ Universidade Estadual de Maringá (UEM), Maringá - PR - Brasil. Doutora em Educação pela Universidade Estadual de Campinas (UNICAMP). Docente do Programa de Pós-Graduação em Educação. ORCID: http://orcid.org/0000-00027666-7253. Lattes: http://lattes.cnpq.br/5273356754482937 E-mail: solangefry@gmail.com

${ }^{2}$ Universidade Estadual de Maringá (UEM), Maringá - PR - Brasil. Mestre em Educação. Doutoranda em Educação pela Universidade Estadual de Maringá (UEM). ORCID: http://orcid.org/0000-0003-1356-537X. Lattes: http://lattes.cnpq.br/6822009557280268.E-mail: luvernaschi@gmail.com

${ }^{3}$ Universidade Estadual do Paraná (UNESPAR), Apucarana - PR - Brasil. Doutor em Educação. Docente colaborador na Universidade Estadual do Paraná (UNESPAR). ORCID: http://orcid.org/0000-0002-9068-1983. Lattes: http://lattes.cnpq.br/5323133721973971.E-mail: jr_oliveira1979@hotmail.com
} 
ABSTRACT: This study is part of the discussion about the current context of teacher education influenced by the dictates of the cultural industry. The approach proposed for this work seeks to problematize the aforementioned theme supported by the theoretical references of the Frankfurt School represented by Theodor W. Adorno, among other thinkers. Thus, we aim to analyze the use of the Critical Theory of Society used in the foundation of stricto sensu research on teacher education in Brazil, from 2014 to 2018. The results point to the importance of the Adornian theory in the critical foundation of studies on the formation of teachers in our country, understood in the process of capitalist production and consumption, that uses art as a maneuver of alienation and massification of the great mass

KEYWORDS: Adorno. Teacher training. Cultural industry.

\section{Introdução}

A expressão indústria cultural, um conceito bastante complexo e ao mesmo tempo autoexplicativo, é decorrente do pensamento filosófico dos alemães da Escola de Frankfurt, Theodor W. Adorno e Max Horkheimer, dentre outros que refletem a respeito do mecanismo de dominação cultural engessado pelo sistema de produção capitalista e representado, principalmente, pelos meios de comunicação de massa. A produção desses autores se refere especificamente ao tipo e à forma de conteúdo que atinge a população (grande massa) sob o comando de poucos (empresários do cinema, $\mathrm{TV}$, jornais, internet e outros), que por meio de conteúdos culturais distorcem o sentido artístico veiculado por esses meios de grande alcance, num processo quase sempre inconsciente de massificação e homogeinização da cultura, das pessoas, dos conteúdos, do poder crítico e reflexivo, da análise e do pensamento autônomo. Em outras palavras, esses pensadores discutem como os bens culturais se tornam mercadorias, numa cadeia que objetiva lucros, havendo menos arte e mais alienação e consumo (ADORNO; HORKHEIMER, 1985).

Para Adorno (2010), na sociedade gerida pelos interesses do capital, a indústria cultural promove a conversão da formação cultural (Bildung) em semiformação ou semicultura (Halbbildung). Por meio da massificação da cultura, há a fragmentação e o esfacelamento da possibilidade de desenvolvimento de consciências críticas. Dessa forma, o sentido de formação, que é atribuído à educação contemporânea, pode não assegurar o desenvolvimento de indivíduos munidos de sensibilidade e consciência verdadeira acerca de seu papel no processo de transformação da atual situação e principalmente de sua capacidade de autonomia intelectual.

Adorno (1995, p. 141) postula que a educação não deve conduzir nem a um processo de "modelagem de pessoas", nem à mera transmissão de conhecimentos, mas à "produção de uma consciência verdadeira”. Em outras palavras, a educação deve primar pela emancipação, 
possibilitando que educadores e educandos compreendam o desenrolar dos processos e eventos sociais dos quais fazem parte.

Com base nesse referencial teórico analisamos o uso da Teoria Crítica da Sociedade em pesquisas stricto sensu sobre formação docente no Brasil, entre os anos de 2014 a 2018 . A pesquisa se justifica por estar estritamente relacionada à necessidade de formação crítica e reflexiva do professor na atualidade, uma vez que o sistema capitalista e a indústria cultural exercem forte influência nos processos de formação e alienação humana.

Para a elaboração do artigo, selecionamos pesquisas stricto sensu cadastradas no banco de teses e dissertações na Coordenação de Aperfeiçoamento de Pessoal de Nível Superior - Capes, defendidas no período de 2014 a 2018. Num primeiro momento, selecionamos 31 (trinta e um) trabalhos, no entanto, a partir de uma leitura mais criteriosa, descartamos 09 (nove) deles, por não atenderem aos critérios de nossa pesquisa. Assim sendo, analisamos 22 (vinte e dois) trabalhos, sendo 06 (seis) teses e 16 (dezesseis) dissertações. Os descritores de busca para a localização dos títulos e análise dos resumos foram combinados em: "indústria cultural, formação docente e Theodor W. Adorno". Os termos foram inseridos na busca de maneira combinada, utilizando os operadores booleanos (and/e, or/ou e not/não), por exemplo, “indústria cultural and formação docente and Adorno", caracterizando distintas combinações.

Para a análise do material, elaboramos um quadro no qual consta a distribuição das pesquisas por regiões brasileiras e por esfera administrativa/instituição de pós-graduação. Em seguida, elaboramos quatro categorias semânticas de análise, segundo a proposta de Bardin (2016), assim constituída: Formação docente para a Educação Básica e implicações da indústria cultural em disciplinas de Educação Física, Filosofia, Matemática e Sociologia (5); Formação da dimensão estética docente - TV, cinema, música e obra literária (8); Percepção dos feitos da indústria cultural na formação inicial de professores (5); e, Implicações da indústria cultural na formação e atuação docente (4).

O Quadro 1 apresenta a distribuição das 22 (vinte e duas) pesquisas analisadas, oriundas das cinco regiões brasileiras, divididas em tipo de pesquisa (Teses ou Dissertações) e subdivididas de acordo com as esferas administrativas a que pertencem. 
Quadro 1 - Distribuição das pesquisas por regiões brasileiras e por esfera administrativa/instituição de pós-graduação

\begin{tabular}{|c|c|c|c|c|c|c|}
\hline \multirow{2}{*}{$\begin{array}{c}\text { Regiões } \\
\text { Brasileiras }\end{array}$} & \multicolumn{2}{|c|}{$\begin{array}{c}\text { Teses (T) } \\
\text { Dissertações (D) }\end{array}$} & \multicolumn{3}{c|}{ Esferas Administrativas } & \multirow{2}{*}{ TOTAL } \\
\cline { 2 - 6 } & T & D & $\begin{array}{c}\text { Públicas } \\
\text { Federais }\end{array}$ & $\begin{array}{c}\text { Públicas } \\
\text { Estaduais }\end{array}$ & Privadas & \\
\hline Norte & - & 1 & 1 & - & - & 1 \\
\hline Nordeste & 1 & 1 & 1 & 1 & - & 2 \\
\hline Centro-Oeste & 1 & 1 & 2 & - & - & 2 \\
\hline Sul & 1 & - & - & 1 & - & 1 \\
\hline Sudeste & 3 & 13 & 8 & 3 & 5 & 16 \\
\hline TOTAL & $\mathbf{6}$ & $\mathbf{1 6}$ & $\mathbf{1 2}$ & $\mathbf{5}$ & $\mathbf{5}$ & $\mathbf{2 2}$ \\
\hline
\end{tabular}

Fonte: Elaboração própria, a partir de análise em teses e dissertações pesquisadas na Capes (2019).

Conforme os dados do quadro 1, das 22 (vinte e duas) pesquisas que se valeram dos pressupostos da Teoria Crítica da Sociedade, um expressivo número foi produzido na região sudeste (72,7\%), seguidas pela produção das regiões nordeste e centro-oeste, com 9,1\% cada uma; e na sequência as regiões norte e sul, com 4,5\% cada uma delas; representando a menor quantidade de trabalhos.

Grande parte das teses e dissertações analisadas é proveniente de instituições públicas federais (54,6\%); já as universidades públicas estaduais e as instituições privadas respondem por 22,7\%, respectivamente.

Na sequência, apresentamos uma síntese dos 22 (vinte e dois) trabalhos analisados, os quais foram organizados em 04 (quatro) categorias semânticas, na ordem alfabética dos respectivos autores das teses e dissertações.

\section{Formação docente para a Educação Básica e implicações da indústria cultural em disciplinas de Educação Física, Filosofia, Matemática e Sociologia}

Nessa primeira categoria reunimos cinco pesquisas, sendo uma tese e quatro dissertações. Bandeira (2017), em sua tese intitulada "Razão instrumental, pragmatismo e suas interfaces com a formação de professores de educação física: reflexões a partir do estágio supervisionado curricular obrigatório", teve como objetivo compreender como se constroem e articulam os fundamentos teóricos do pragmatismo e da razão instrumental, tendo em vista as concepções hegemônicas de formação de professores de educação física e de estágio supervisionado curricular obrigatório, estas veiculadas nas produções científicas da pós-graduação stricto sensu, defendidas entre 2002 
e 2015. Para atender ao objetivo proposto, além de discorrer sobre o pragmatismo e formação de professores em John Dewey, se valeu das contribuições da Teoria Crítica Frankfurtiana para essa mesma finalidade e, por último, investigou sobre o estágio obrigatório na formação de professores de Educação Física. Sobre esse último aspecto, selecionou 05 (cinco) teses e 09 (nove) dissertações que compuseram seu corpus de análise. A esse respeito, a pesquisadora, com base em Theodor W. Adorno, alega que essa teoria contribui com o entendimento do estudo, uma vez que pode evidenciar que, mesmo em pesquisas que se sustentam da categoria da práxis e da crítica, revelam contradições, visto que se mostram conservadoras, além do que as instituições de ensino legitimam pressupostos epistemológicos, filosóficos e teóricos próprios do modo de produção capitalista encarnado na indústria cultural. Dessa forma, essa constatação mostra o fracasso da formação humana, da escola e da profissão docente, que muitas vezes não vê o trabalho como um princípio educativo.

Andrade (2014), em sua dissertação, cujo título é "Formação de Professores de Sociologia: possibilidade de crítica à sociedade de massas”, teve como objetivo descrever a trajetória de formação do professor dessa disciplina, entendida como possibilidade de crítica a essa forma de funcionamento e organização social. Com esse intuito, realizou estudo autobiográfico considerando aspectos teóricos e práticos da formação de um professor da disciplina de Sociologia. Para o estudo de sociedade de massas e a análise do referido estudo fez uso da teoria de Theodor W. Adorno e de Max Horkheimer, dentre outros autores que discutem a manifestação dos interesses da burguesia e de sua hegemonia cultural. O texto de Andrade (2014) apresenta uma reflexão sobre a formação docente e estabelece um discurso sobre o ensino de Sociologia como possibilidade de crítica à sociedade de massas, tendo por base as teorias sociológicas e a práxis entre educador e educando suscitada pelo conhecimento sociológico. Ou seja, esse saber leva o estudante a uma atitude reflexiva a respeito de sua prática social, retirando-o de uma condição passiva e alienada.

Jesus (2017) em sua dissertação, cujo título é "Docência de Filosofia e a formação inicial nos cursos de licenciaturas", buscou analisar a formação do professor na área de Filosofia. Para isso, o pesquisador inicialmente discorreu sobre algumas características históricas da trajetória da disciplina de Filosofia na educação escolar brasileira; a seguir, apresentou um panorama analítico de como os teóricos e professores de Filosofia discutem a formação de docentes para essa área de conhecimento. Por fim, analisou, criticamente, os suportes pedagógicos e metodológicos do currículo do curso de Filosofia da Universidade Federal de São João Del-Rei, bem como refletiu sobre a forma como são elaboradas as diretrizes para formação de professores em nível médio para atuarem nesta área de humanas. O autor instiga o professor e o leitor a refletirem sobre a importância de ensinar o aluno a 'filosofar' ou a ensinar a 'história da Filosofia'. Adverte também que o ensino dessa disciplina deve ser realizado de forma transdisciplinar e que há muitos desafios a serem enfrentados no campo em 
questão. Nesse sentido, os envolvidos nesse processo precisam colaborar com reflexões sobre a formação de professores e alunos, a fim de que ocorram mudanças na formação inicial do professor de Filosofia.

Lucas (2017) defendeu a dissertação intitulada "A dimensão estética na trajetória formativa: narrativa de um professor", cujo objetivo foi compreender seu caminho de formação como pesquisador, levando em conta aspectos de sua vida pessoal, acadêmica e profissional, por meio de narrativa autobiográfica e da técnica "Colcha de Retalhos". Em seu estudo, o autor abordou diferentes espaços e tempos de formação, visando a análise da percepção, interpretação e compreensão dos fatos por ele apresentados. Para atender a esse propósito, o autor enfatizou o conceito de educação estética, autonomia e emancipação, de Theodor W. Adorno e de outros pensadores da sociedade crítica, que afirmam que a manipulação estética decorrente dos efeitos da indústria cultural gera o processo de semiformação. Dentre as ponderações do pesquisador, a que diz respeito à importância das reflexões acerca dos processos que configuram a formação de sua identidade e subjetividade são relevantes, porque as narrativas são um recurso no processo de formação docente, pois nelas o professor "[...] compreende sua trajetória e é capaz de encontrar razões e emoções que compõem sua existência [...]" (LUCAS, 2017, p. 90), ao refletir sobre as marcas cronológicas de sua formação, levando-o a um redirecionamento daquilo que aprisiona o ensinar e o aprender, considerando a estética da desigualdade escolar que permearam sua formação matemática.

Magalhães Júnior (2014) dissertou sobre "Educação Física escolar, esporte e (semi) formação: reflexões a partir da Teoria Crítica da Sociedade”, objetivando problematizar o modo como o esporte tem sido pensado na formação de professores de Educação Física. O pesquisador, fundamentado na Escola de Frankfurt, inicialmente apresentou um estudo teórico sobre a formação na sociedade atual, atravessada pelo capitalismo em seu estágio atual e pelas implicações da indústria cultural na constituição das subjetividades humanas. Além disso, refletiu sobre a possibilidade de uma fruição estética no esporte. Por último, analisou de forma crítica duas obras que fundamentam a formação do professor de Educação Física, presentes em ementas das disciplinas, no curso de licenciatura na Universidade Federal de Lavras. Mediante o estudo, o autor concluiu sobre a necessidade de se repensar o modo como o esporte vem sendo trabalhado como elemento formativo pela Educação Física escolar, sobretudo como espaço de reflexão, enquanto disciplina do conhecimento.

\section{Formação da dimensão estética docente: TV, cinema, música e obra literária}

Oito dissertações compõem a segunda categoria de análise. Barros (2014) pesquisou sobre “A dimensão estética da experiência docente: um estudo sobre a contribuição da obra literária". O autor 
analisou criticamente a obra "A Língua de Eulália: novela sociolinguística", de Marcos Bagno, objetivando compreender o sentido da dimensão estética nos processos pedagógicos presentes na citada produção. Dentre outros teóricos críticos, o pesquisador recorreu aos estudos de Theodor W. Adorno nos aspectos relacionados aos parâmetros da estética da indústria cultural e de massificação da cultura. Barros (2014) concluiu que o seu estudo permitiu compreender que o material analisado tem um papel significativo no processo formativo do professor, examinado pelo viés dos processos de emancipação e massificação cultural, em que a arte é tida como experiência que deve ser considerada como uma forma de educação mais humanizadora.

Bet (2015), em sua dissertação intitulada “Televisão e formação na era digital: um exame crítico das pretensões formativas do Programa Salto para o Futuro", produzido pela TV Brasil, gerida pelo Ministério da Educação (MEC), teve como objetivo verificar se o conteúdo do referido programa educativo exibido pela TV Escola, veicula a relação conteúdo e forma, apresentado por mensagens com apelo formativo, ou, ao contrário, semiformativos. $\mathrm{O}$ episódio analisado pela autora diz respeito à formação continuada de professores e gestores da Educação Básica, o qual demonstrou que há predominância da forma sobre o conteúdo, isto é, o seu formato se assemelha ao do telejornalismo tradicional; também foi observado o clichê de professor que no futuro, em meio a um "salto" sobre as implicações sociais, políticas, econômicas e outras do atual contexto, resolve os problemas da educação mediante o uso de tecnologias audiovisuais. Diante dessas contradições, Bet (2015) conclui que o referido programa poderia se ater a um caráter pedagógico, revelando os mecanismos de recusa e resistência tidos como a representação do real.

Marcos (2018) dissertou sobre "O ensino de música nas escolas públicas paulistas: entre a formação e a semiformação", objetivando analisar as Orientações Curriculares e Didáticas de Arte para os anos iniciais do Ensino Fundamental em música em escolas estaduais de São Paulo, com o intuito de averiguar o tipo de formação pretendida no material analisado. Apesar de a análise ser em parte dirigida à formação dos estudantes, o pesquisador correlacionou o resultado da aprendizagem deles à formação de seus professores, aspecto também contemplado no material analisado, bem como no aporte teórico da Escola de Frankfurt, objeto de nosso estudo. Em se tratando desse aspecto, Marcos (2018) salientou que em verdade, o que ocorre é a semiformação do professor, ancorada pela densidade do conteúdo de música, a insuficiente formação em serviço e a falta de tempo e incentivo para os docentes se capacitarem fora do contexto escolar, por iniciativa própria. Nesse sentido, se a emancipação ocorre na relação autonomia e adaptação, os documentos analisados apontam para a segunda, uma vez que a formação continuada, os recursos materiais, os espaços físicos, até mesmo os conteúdos precisam ser adaptados ao que está disponível pela indústria cultural sonora socialmente disponibilizada. 
Peres (2016), na dissertação intitulada "Entre choques, cortes e fissuras - a (semi)formação estética: uma análise crítica da apropriação de filmes na educação escolar", teve como objetivo compreender a forma com que professores do Ensino Fundamental I propõem e organizam a utilização do filme como recurso e instrumento didático no momento de sua prática. Para isso, inicialmente a pesquisadora realiza reflexões sobre a inserção do filme na educação escolar, entendida como perspectiva de reeducação de sentidos e/ou como veiculação do caráter ideológico dos produtos da indústria cultural. A partir dos depoimentos de 14 (quatorze) professores investigados, a pesquisadora constatou que a não intencionalidade consciente do docente demarca o caráter semiformativo, apontado como ilustração ou momento de lazer, presente nas instituições educativas pesquisadas. Enfim, Peres (2016, p. 227) afirma que não encontrou nos depoimentos dos entrevistados “[...] elementos de uma didática fílmica associada intrinsecamente a seus termos formais, estéticos e estruturais, que vá além do que é expresso pelo seu conteúdo fetichizado". Embora o objetivo principal da autora não tenha sido inicialmente a formação docente, mas a sua ação, com o desenrolar de sua investigação, verificou a necessidade de se repensar o uso das mídiasimagético-eletrônicas no contexto da formação dos alunos do curso de Pedagogia.

Rosa (2017), em sua dissertação intitulada "O cinema como possibilidade a formação docente", teve como objetivo refletir e problematizar como esse recurso audiovisual pode ser um mediador qualitativo para a formação de professores, objetivando compreender o trabalho docente, a partir da análise de dois filmes de François Truffaut: "Na idade da inocência" (1976) e "Os incompreendidos" (1959). Para tanto, a autora analisou, nas referidas obras, as características relacionadas à educação, bem como sua relação com a formação estética do professor, principalmente no que se refere aos aspectos de conteúdo e forma relacionados ao espaço escolar. A pesquisadora concluiu que a utilização de filme como aparato tecnológico do professor apresenta pontos positivos, pois retrata aspectos do cotidiano, desperta emoções e sensações, entretanto, é uma representação do real e a realidade precisa ser problematizada e analisada criticamente.

Sousa (2018) apresentou a dissertação intitulada "Educação profissional: tessituras da formação e da experiência docente", com o objetivo de analisar a formação docente, na perspectiva da estética, numa instituição de educação profissional, com o intuito de compreender como os valores estéticos podem contribuir no desenvolvimento de práticas pedagógicas dos docentes que atuam numa instituição de educação profissional em Minas Gerais. A pesquisa é de cunho qualitativo, numa abordagem de estudo de caso a respeito da oferta de capacitação continuada de caráter cultural a partir do uso do cinema em oficinas fílmicas, destinadas a professores da educação profissional de nível técnico e superior. A autora analisou 14 (quatorze) entrevistas semiestruturadas e documentos institucionais. Com a finalidade de refletir sobre a formação docente na perspectiva estética, o estudo 
traz reflexões sobre alguns conceitos da Teoria Crítica da Sociedade como: semiformação, formação cultural, razão instrumental e valores estéticos. A esse respeito, Sousa (2018, p. 141) assevera, essa iniciativa possibilita “[...] um olhar crítico sobre as práticas desses profissionais enquanto responsáveis pela formação de outros indivíduos que também estão sendo formados para atender as exigências do sistema capitalista [...]”, com base nas reflexões críticas das produções fílmicas trabalhadas no referido curso.

Weixter (2016) defendeu a dissertação nominada "A catarse musical na reeducação dos sentidos: formação, música e educação em Theodor Adorno e Georges Snyders”. Embora a autora não tenha investigado exclusivamente a relação indústria cultural e formação docente, achamos conveniente incluir sua pesquisa em nossa análise porque ela discute a relação educação, música e estética. Trata-se de um estudo teórico-analítico fundamentado nos estudos críticos da sociedade. A autora investiga as formas em que essas concepções podem contribuir com a formação estéticocultural de professores e alunos, com o objetivo de destacar a importância do conceito da catarse adorniana para a discussão em torno da Bildung (formação cultural), em contraposição à Halbbildung (semiformação). A pesquisadora infere que a educação almejada só será possível mediante a formação crítica dos professores nas dimensões estético-cultural e, que a compreensão da natureza humana não se limita aos interesses do mercado, que reduz os valores humanos e coíbe a equidade de direitos e de justiça social.

Xavier (2017) dissertou sobre "Infância e cinema: implicações para a formação das crianças na sociedade contemporânea", problematizando o acesso precoce de crianças em suportes que veiculam imagens e recursos audiovisuais. Para a autora, os professores se mostram "indiferentes" a respeito dessa realidade que afeta o comportamento das pessoas em geral. Com base nessa constatação, Xavier (2017) objetivou analisar como o cinema retrata a criança na sociedade contemporânea de acordo com o referencial teórico adorniano. Além de analisar criticamente os filmes "Na idade da inocência", de François Truffaut (1976) e "Minions", de Pierre Coffin e Kyle Balda (2015), a pesquisadora participou do Projeto de Pesquisa e Extensão "O cinema como uma experiência inovadora da formação cultural docente II", aspecto que condiz com a proposição do presente texto, uma vez que discutimos a relação indústria cultural e formação docente. A esse respeito, a pesquisadora afirma a necessidade dos professores se relacionarem de uma forma crítica com as produções artísticas e culturais provindas da indústria cultural que tematizam a infância. 


\section{Percepção dos feitos da indústria cultural na formação inicial de professores}

Cinco pesquisas, sendo três teses e duas dissertações, formam a terceira categoria semântica. Barcellos (2014) defendeu a tese "A experiência estética na formação do docente da educação básica", com o objetivo de investigar a importância da formação estética nos cursos de Pedagogia, considerando que tal procedimento contribui para o processo educativo, principalmente na capacitação docente ao enfrentar os preceitos da indústria cultural. Participaram da pesquisa 04 (quatro) instituições de ensino superior, 01 (uma) estrangeira (Catalunha, Espanha) e três localizadas no interior do estado de São Paulo. Além disso, a autora analisou sob a luz da Teoria Crítica da Sociedade o ementário dos cursos de Pedagogias dessas instituições e aplicou questionário a estudantes do último semestre do referido curso, buscando conhecer o background dos estudantes, conceito de estética, objeto artístico, atividades artísticas desenvolvidas durante o curso, dentre outras informações. De modo geral, percebemos que Barcellos (2014) constatou em sua análise que, mesmo que haja intenção de uma formação docente reflexiva, apontando para uma participação mais autônoma e ética dos sujeitos que participam do processo formativo, as mantenedoras precisam garantir condições para que essa superação realmente ocorra.

Bido (2018) produziu a tese "Formação de professores no Instituto Federal do Paraná à luz da teoria crítica”, para isso analisou a concepção de formação em cursos de licenciatura do IFPR, contrastando-a com o princípio formativo orientador da sua criação, bem como buscou compreender a ambivalência do seu fundamento formativo no âmbito global da educação funcional e adaptativa. Os documentos que compõem o corpus da pesquisa são provenientes de organizações internacionais que versam sobre o projeto educacional global para os países subdesenvolvidos e emergentes; as orientações oficiais sobre implantação das licenciaturas no Brasil, dos Institutos Federais e do IFPR; e seis Projetos Pedagógicos de Cursos (PPCs) de licenciaturas em funcionamento no IFPR (dois em Química e quatro em Física), a respeito da finalidade da educação atual frente aos ditames do sistema produtivo. O material referido é analisado sob a égide dos conceitos da Teoria Crítica da Sociedade, racionalidade crítica, autonomia e emancipação. Dentre outros aspectos, tratados pelo autor sobre a adaptação da educação para atender as demandas do sistema produtivo, adverte sobre os PPCs estudados, que apesar de apontarem para uma possibilidade de formação crítica e autorreflexiva, nesse Instituto, há a prevalência da forma sobre o conteúdo, do enfoque social sobre o cultural e que pela observância do desenvolvimento de competências e habilidades se fortalece como reprodutor da lógica funcionalista e instrumental.

Manfré (2014) apresentou a tese intitulada "O mal-estar docente e os limites da experiência no tempo presente: uma leitura frankfurtiana”, tendo como objetivo geral investigar as estratégias que 
os docentes desenvolvem para a constituição do seu bem-estar. Para tanto, busca analisar as relações estabelecidas entre mal-estar docente, formação docente e semiformação, “[...] elementos estes não clarificados e não explicitados pelos estudiosos da temática mal-estar docente na atualidade" (MANFRÉ, 2014, p. 21). A autora discorre também sobre as políticas de formação docente que devem considerar, no processo formativo, reflexões sobre teoria e prática. A pesquisadora adverte, conforme estudos que fundamentaram os aspectos de formação inicial e continuada de professores, que "[...] as transformações sociais provocadas pelo advento da massificação do ensino, das novas tecnologias, da globalização, demarcaram a baixa valorização do trabalho do professor e o investimento na educação" (MANFRÉ, 2014, p. 187), elementos que têm causado o mal-estar docente na atualidade.

Carvalho (2018) dissertou sobre "A estética da formação do professor no ensino superior: narrativas (auto) biográficas como forma de mediação nas práticas pedagógicas e de gestão da sala de aula", com o objetivo de compreender a importância desses procedimentos como possibilidade de mediação da gestão de sala de aula na formação do pesquisador que atua como professor universitário, com o intuito de desenvolver a autonomia e emancipação dos sujeitos. O material analisado pela pesquisadora foi constituído pelo dispositivo formativo "Colcha de Retalhos". Nele, as trajetórias de vida são narradas e compartilhadas, permitindo aos participantes “[...] (re) significar suas experiências, e, portanto, tornarem-se mais conscientes de si, o que lhes proporciona autonomia e emancipação, via estética" (CARVALHO, 2018, p. 14), fato que condiz com os pressupostos adornianos. Participaram da pesquisa 06 (seis) professores de vários cursos de uma instituição de Ensino Superior de Brasília, Centro Universitário do Distrito Federal (UDF), e que também eram alunos do Mestrado Acadêmico em Educação da Universidade Cidade de São Paulo (UNICID) em 2018. Segundo a pesquisadora, a prática reflexiva se mostra relevante na intervenção da educação bancária, bem como na formação da dimensão estética docente, que compreende o desenvolvimento da autonomia e da emancipação dos sujeitos envolvidos no processo de ensino e aprendizagem.

Gontijo (2018) defendeu a dissertação intitulada "Semiformação e indústria cultural: percepções de docentes nos cursos presenciais de Pedagogia do sudoeste goiano”, objetivando compreender a atual conjuntura educacional e as concepções formativas de docentes que atuam nesses cursos, bem como os mecanismos de ideologia e da indústria cultural que perpassam essas formações. Para conhecer a concepção formativa dos referidos docentes, a pesquisadora se fundamentou em estudos de Theodor W. Adorno, Max Horkheimer e Herbert Marcuse, dentre outros. Na parte empírica, 36 (trinta e seis) docentes de 05 (cinco) instituições de ensino superior daquela região responderam individualmente uma entrevista semiestruturada e um questionário sociodemográfico. Os resultados apontam que a maioria dos participantes da pesquisa representam uma formação docente orientada para a resistência e opõem-se à formação apenas de caráter instrumental, entretanto 
a pesquisadora constatou também que, embora em menor número, há concepções permeadas pela indústria cultural que propagam a semiformação.

\section{Implicações da indústria cultural na formação e atuação docente}

Quatro trabalhos formam a última categoria analisada, duas teses e duas dissertações. Dias (2018) defendeu a tese nomeada "Formação de professores e educação inclusiva: uma análise à luz da Teoria Crítica da Sociedade", cujo objetivo foi caracterizar as abordagens da Educação Inclusiva nos cursos de licenciatura de uma universidade baiana, que tem tradição em formar professores de todas as áreas de conhecimento. Com esse intuito, a pesquisa foi fundamentada em autores críticos como Theodor W. Adorno, dentre outros. Na parte prática, se valeu da abordagem qualitativa do tipo estudo de caso, em que entrevistou individualmente 07 (sete) professores de 11 (onze) cursos de licenciatura. Além disso, analisou documentos legais, como Projetos Acadêmico Curriculares dos Cursos (PACs), fluxogramas e ementas de disciplinas. A pesquisadora constatou que a maioria dos cursos analisados não contempla a discussão da educação inclusiva em seus currículos, e os demais o fazem de forma incipiente, assim como as concepções de educação inclusiva presentes nas propostas pedagógicas e nos componentes curriculares apontam o viés técnico e instrumental na abordagem dos temas, condizente, portanto, à ideologia da racionalidade tecnológica. Apesar de os docentes entrevistados reconhecerem a importância dos conhecimentos sobre educação inclusiva, afirmaram que esses não fizeram parte de sua formação. A pesquisadora identificou também "[...] o caráter reducionista e fragmentado da formação, marcada pela ênfase na cisão entre teoria e prática, pautada na valorização dos meios, caracterizando o viés instrumental, marca da formação na contemporaneidade" (DIAS, 2018, p. 09), alicerçada nos ditames da indústria cultural.

Silva (2017) produziu a tese "As relações entre a formação/qualificação de professores e o processo pedagógico reveladas em oito pesquisas empíricas de sala de aula", com o objetivo de compreender as relações entre a formação/qualificação de professores e o processo pedagógico em pesquisas empíricas (dissertações) realizadas entre os anos de 2010 a 2014, no curso de PósGraduação da PUC/MG, que analisaram o currículo materializado na sala de aula. Para estabelecer essa compreensão, a pesquisadora se valeu de estudo de caso, de caráter qualitativo, a partir dos pressupostos teóricos da Teoria Crítica, fundamentada principalmente em Theodor W. Adorno e na literatura que trata da formação docente. Silva (2017) confrontou críticas que atualmente são atribuídas à formação docente com o resultado dos trabalhos por ela analisados, bem como comparou se a relação entre lacunas pedagógicas pode ser ancorada na formação de professores, aspecto que revelou que a formação está substanciada pela “[...] Indústria Cultural, materializada pela 
fragmentação dos currículos dos cursos de formação/qualificação docente, pela desarticulação entre a teoria e a prática, pela descaracterização dos estágios curriculares [...]” (SILVA, 2017, p. 08). Além disso, constatou que o perfil do futuro docente está objetivado em dificuldades básicas em leitura, escrita e interpretação; ao passo que o professor formador tem dificuldades para realizar seu trabalho pedagógico; tudo isso somado às reformas pedagógicas que não possibilitam efeitos qualitativos nos processos de formação docente.

Marfim (2017), em sua dissertação intitulada "Sociedade informacional entre demandas e contradições: os limites e as potencialidades para integrar as Tecnologias Digitais de Informação e Comunicação às práticas educativas na formação inicial do pedagogo - estudo de caso junto aos licenciandos da Universidade Federal de São Paulo", teve como objetivo investigar em que medida os processos formativos que inserem e tematizam a integração das tecnologias digitais de informação e comunicação (TDIC) ao campo da Educação, no curso de Pedagogia da Universidade Federal de São Paulo (UNIFESP), contribuem para a formação de seus licenciandos. Além de discorrer sobre os aspectos históricos contextuais contemporâneos referentes ao âmbito econômico, cultural, político e de sociabilidade imbricadas a essas tecnologias e à educação, o autor, pelo viés qualitativo e estudo de caso de caráter instrumental, aplicou e analisou questionário aberto-fechado e entrevista semiestruturada individual a 04 (quatro) estudantes do curso de Pedagogia da Universidade Federal de São Paulo. Marfim (2017) concluiu que o processo formativo dos licenciandos investigados contempla reflexões críticas acerca do trabalho docente, entretanto, o uso pedagógico das tecnologias digitais precisa ser problematizado na dimensão da formação cultural dos investigados.

Santos Neta (2016), em sua dissertação denominada "Formação de professores: um estudo das condições objetivas na implementação do Plano Nacional de Formação de Professores para a Educação Básica - Parfor/UFMA”, teve como objetivo analisar as condições objetivas para o desenvolvimento dos cursos do referido Programa implantado na Universidade Federal do Maranhão, especificamente nos municípios de Humberto de Campos e Coroatá. Além de realizar estudos teóricos sobre a formação de docentes no Brasil a partir da década de 1990, a pesquisadora analisou as condições sociais, econômicas, culturais e humanas para o desenvolvimento do Parfor sob o olhar de 29 (vinte e nove) sujeitos que responderam individualmente a entrevistas semiestruturadas, sendo 16 (dezesseis) professores-alunos, 08 (oito) professores-formadores, 02 (dois) coordenadores de curso, 01 (um) coordenador geral do Programa e 02 (dois) coordenadores locais das Secretarias Municipais de Educação. Com base nas ideias do filósofo Theodor W. Adorno, que trata de questões como semiformação e emancipação, e de outros pesquisadores que discutem a temática formação de professores, Santos Neta (2016) adverte que há lacunas e limites das condições físicas, materiais, culturais e humanas na implementação do Parfor, aspecto que demanda uma releitura do papel dos 
órgãos nele envolvidos. Salienta também a necessidade de uma formação para a autonomia, emancipação e resistência aos ditames da indústria cultural e da semiformação observados em sua investigação em cursos de licenciatura.

\section{Considerações finais}

Conforme proposto, na presente pesquisa analisamos o uso da Teoria Crítica da Sociedade utilizada na fundamentação de pesquisas stricto sensu sobre formação docente no Brasil, entre os anos de 2014 a 2018.

Com base na seleção e análise das pesquisas que compõem esse estudo, consideramos valorosa a escolha dos pressupostos filosóficos adornianos e de seus contemporâneos utilizados pelos autores das teses e dissertações que analisamos, ao utilizá-los para interpretar, discutir e referenciar suas investigações, considerando a necessidade de correlacionar a formação de professores com o atual contexto da indústria cultural, que prima pela negação dos sujeitos e leva-os não só ao consumo do produto cultural, mas dos seus correlatos produzidos em ciclos intermináveis.

Enfim, em nossa apreciação sobre o material estudado, percebemos a grande relevância de se compreender a formação crítica de professores e alunos, bem como as reflexões sobre a semiformação presentes nesses processos educativos atuais. Entretanto, são necessários outros estudos envolvendo o tema em pauta, pois quanto maior é o grau de consciência do professor sobre as relações de produção e consumo, maior será a sua capacidade profissional formar alunos críticos e autônomos.

Acreditamos que o ato de ensinar deve sobrepujar o domínio exercido pelos mecanismos de sedução da indústria cultural. Mas, para que isso ocorra, é necessário que haja consciência de tal domínio, pois como postula Adorno (2010, p. 39), “a única possibilidade de sobrevivência que resta à cultura é a autorreflexão crítica sobre a semiformação, em que necessariamente se converteu".

\section{REFERÊNCIAS}

ADORNO, T.W.; HORKHEIMER, M. Dialética do esclarecimento: fragmentos filosóficos. Rio de Janeiro: Jorge Zahar, 1985.

ADORNO, T. W. Educação e emancipação. 3. ed. São Paulo: Paz e Terra, 1995.

ADORNO, T. W. Teoria da semiformação. In: PUCCI, B.; ZUIN, A. A. S.; LASTÓRIA, L. A. C. (Orgs.). Teoria crítica e inconformismo: novas perspectivas de pesquisa. Campinas: Autores Associados, p. 10-40, 2010. 
ANDRADE, R. A. O. Formação de Professores de Sociologia: possibilidade de crítica à sociedade de massas. 2014. 156 f. Dissertação (Mestrado em Educação). Universidade Federal de Rondônia, Porto Velho, 2014.

BANDEIRA, L. B. Razão instrumental, pragmatismo e suas interfaces com a formação de professores de educação física: reflexões a partir do estágio supervisionado curricular obrigatório. 2017. 282 p. Tese (Doutorado em Educação). Universidade Federal de Goiás, Goiânia, 2017.

BARCELlOS, A. C. K. A experiência estética na formação do docente da educação básica. 2014. 107 f. Tese (Doutorado em Educação). Universidade Metodista de Piracicaba, SP, 2014.

BARDIN, L. Análise do conteúdo. São Paulo: Edições 70, 2016.

BARROS, G. B. de. A dimensão estética da experiência docente: um estudo sobre a contribuição da obra literária. 2014. 73 f. Dissertação (Mestrado em Educação). Universidade Cidade de São Paulo, SP, 2014.

BET, D. S. Televisão e formação na era digital: um exame crítico das pretensões formativas do Programa Salto para o Futuro. 2015. 187 f. Dissertação (Mestrado em Educação). Universidade Federal de São Carlos, SP, 2015.

BIDO, J. M. Formação de professores no Instituto Federal do Paraná à luz da teoria crítica. 2018. 287 f. Tese (Doutorado em Educação). Universidade Estadual de Maringá, PR, 2018.

CARVALHO, A. P. D. A estética da formação do professor no ensino superior: Narrativas (auto)biográficas como forma de mediação nas práticas pedagógicas e de gestão da sala de aula. 2018. 152 f. Dissertação (Mestrado em Educação). Universidade Cidade de São Paulo, SP, 2018.

DIAS, V. B. Formação de professores e educação inclusiva: uma análise à luz da Teoria Crítica da Sociedade. 2018. 263 f. Tese (Doutorado em Educação e Contemporaneidade). Universidade do Estado da Bahia, Salvador, 2018.

GONTIJO, E. S. Semiformação e indústria cultural: percepções de docentes nos cursos presenciais de pedagogia do sudoeste goiano. 2018. 167 f. Dissertação (Mestrado em Educação). Universidade Federal de Goiás, Jataí, GO, 2018.

JESUS, W. E. Docência de filosofia e a formação inicial nos cursos de licenciaturas. 2017. 134 f. Dissertação (Mestrado Profissional em Educação). Universidade Federal de Lavras, MG, 2017.

LUCAS, G. A. de. A dimensão estética na trajetória formativa: narrativa de um professor. 2017. 98 f. Dissertação (Mestrado em Educação). Universidade Cidade de São Paulo, SP, 2017.

MAGALHÃES JÚNIOR, C. A. Educação Física Escolar, Esporte e (Semi) Formação: Reflexões a partir da Teoria Crítica da Sociedade. 2014. 85 f. Dissertação (Mestrado Profissional em Educação). Universidade Federal de Lavras, MG, 2014.

MANFRÉ, A. H. O mal-estar docente e os limites da experiência no tempo presente: uma leitura frankfurtiana. 2014. 212f. Tese (Doutorado em Educação) Universidade Estadual Paulista "Júlio de Mesquita Filho", Presidente Prudente, SP, 2014. 
MARCOS, M. H. de. O ensino de música nas escolas públicas paulistas: entre a formação e a semiformação. 2018. 135 f. Dissertação (Mestrado em Educação Escolar). Universidade Estadual Paulista "Júlio de Mesquita Filho", Faculdade de Ciências e Letras, (campus de Araraquara), SP, 2018.

MARFIM, L. Sociedade informacional entre demandas e contradições: os limites e as potencialidades para integrar as Tecnologias Digitais de Informação e Comunicação às práticas educativas na formação inicial do pedagogo - estudo de caso junto aos licenciandos da Universidade Federal de São Paulo. 2017. 267 f. Dissertação (Mestrado em Educação). Universidade Federal de São Paulo, Guarulhos, SP, 2017.

PERES, H. C. Entre choques, cortes e fissuras - a (semi)formação estética: uma análise crítica da apropriação de filmes na educação escolar. 2016. 236 f. Dissertação (Mestrado em Educação Escolar). Universidade Estadual Paulista "Júlio de Mesquita Filho", Faculdade de Ciências e Letras, (campus de Araraquara), SP, 2016.

ROSA, L. M. R. O cinema como possibilidade a formação docente. 2017.174 f. Dissertação (Mestrado Profissional em Educação). Universidade Federal de Lavras, MG, 2017.

SANTOS NETA, A. R. Formação de professores: um estudo das condições objetivas na implementação do Plano Nacional de Formação de Professores para a Educação Básica - PARFOR / UFMA. 2016. 154 f. Dissertação (Mestrado em Educação). Universidade Federal do Maranhão, São Luís, 2016.

SILVA, K. A. S. As relações entre a formação/qualificação de professores e o processo pedagógico reveladas em oito pesquisas empíricas de sala de aula. 2017. $228 \mathrm{f}$. Tese (Doutorado em Educação). Pontifícia Universidade Católica de Minas Gerais, Belo Horizonte, 2017.

SOUSA, E. Educação profissional: tessituras da formação e da experiência docente. 2018. 154 f. Dissertação (Mestrado Profissional em Educação). Universidade Federal de Lavras, MG, 2018.

WEIXTER, R. R.A catarse musical na reeducação dos sentidos: formação, música e educação em Theodor Adorno e Georges Snyders. 2016. 169 f. Dissertação (Mestrado em Educação). Universidade Federal do Espírito Santo, Vitória, 2016.

XAVIER, E. B. C. Infância e Cinema: implicações para a formação das crianças na sociedade contemporânea. 2017. 113 f. Dissertação (Mestrado Profissional em Educação). Universidade Federal de Lavras, MG, 2017.

\section{Como referenciar este artigo}

YAEGASHI, Solange Franci Raimundo; OLIVEIRA, Lucilia Vernaschi de; OLIVEIRA JÚNIOR, Isaias Batista de. Indústria cultural e formação docente: análise de teses e dissertações presentes na capes (2014-2018). Revista Ibero-Americana de Estudos em Educação, Araraquara, v. 14, n. esp. 4, p. 1913-1928, dez., 2019. E-ISSN: 1982-5587. DOI: https://doi.org/10.21723/riaee.v14iesp.4.12918

Data de submissão: 25/06/2019

Data de aceite: $28 / 07 / 2019$

Data de publicação: 01/09/2019 